\title{
GI-MS47-01 | 32 YeARS OF TRAVELS In CRYStallography
}

Garman, Elspeth (University of Oxford, Oxford, GBR)

Crystallography has a proud historical record and current practice of outstanding researchers who were/are women. It is interesting to reflect on why this aspect of our field is a positive outlier in the STEM arena, and also how this can not only be maintained but also improved upon. The Braggs, father and son, contrary to the norm for the times during which they worked, had many women in their research groups (WH Bragg: 10/17 and WL Bragg 4/6 [1]), establishing crystallography as a subject in which women don't just survive, but in which they can excel. Crystallographers trained by the Braggs then became inspiring role models for several more generations of highly successful female researchers.

I have been privileged to know and work with some of these scientists, and in this highly personal account, I will comment on the general attitude and climate towards women in STEM and how it is changing and still needs to improve. I will draw on my experiences as a scientist who happens to be a woman, as well as tracking research on developing new methods in structural biology with which I have been involved during the last 32 years.

[1] Maureen M. Julian, "Women in Crystallography," in Women of Science: Righting the Record, ed. G. Kass-Simon and Patricia Farnes (Bloomington: Indiana University Press, 1990), pp. 342 